\section{Categories for Infection Control: A New Approach from the Centers for Disease Control}

This issue of Infection Control contains the first two sets of guidelines that currently are being sent to all United States hospitals by the Centers for Disease Control (CDC) (See pages 117-146). The specific recommendations for individual aspects of infection control should certainly produce comment, and it seems reasonable to expect a spirited dialogue to be engendered in this journal and elsewhere. However, before we begin evaluation of the individual Guidelines, it may be worthwhile to consider some general aspects of this program by which the Guidelines have been developed.

\section{What's New?}

These Guidelines will receive careful attention from the entire infection control community for three reasons. First, the Guidelines are being released by an agency whose opinions command widespread interest and respect throughout the U.S.A. and in other countries. Second. the Guidelines are grouped into categories that express CDC's view of the relative value of implementation. Third, the Guidelines and their categorization have been assembled by CDC only after an extensive, organized effort to solicit the opinions and advice of a variety of infection control resources outside the CDC itself.

\section{The Source}

Previous infection control guidelines from CDC often have become virtual commandments on given issues. As a crosstown neighbor of CDC, I have come to understand the major impact of a CDC statement. Our cooperative study with CDC on the effect of extending the interval between changes of IV administration tubing appeared in 1979. ${ }^{1}$ The opportunity to view the data and study our interpretation permitted hospitals to take what they considered appropriate action on this matter. Yet for many months afterwards I was surprised to encounter infection control workers who stated that until CDC issued its "official" statement about this, the issue could not be considered in many hospitals or other health care institutions.

I believe this respect for CDC statements occurs for at least three reasons:

(1) As a Federal agency, CDC has stature and access to funding that permit widespread distribution of its statements. Journals often are willing to publish guidelines from this governmental voice. This access often can be supplemented by distribution by the agency itself, on a scale that cannot be matched by most other organizations. Indeed, this is exemplified by the announcements that have preceded the infection control Guidelines. Before the actual Guidelines were received, our hospital received both a letter and a postcard from CDC at different times, heralding the arrival of the Guidelines. Shortly thereafter, a notice about the Guidelines appeared in the Morbidity and Mortality Weekly Report, which is circulated by CDC to about 102,000 people. ${ }^{2}$ This pre-release publicity for the Guidelines, on a scale that could be matched only by larger corporations in the private sector, should certainly be capable of generating interest. 
(2) CDC is not officially a regulatory agency. However, most infection control workers are well aware that CDC personnel serve as consultants or committee members for most of the Federal groups that actually do regulate hospitals, and have significant crosslinks with "voluntary" accrediting agencies like the Joint Commission on Accreditation of Hospitals. Thus, when hospital personnel see Guidelines from CDC, they may perceive that these recommendations are just a small step away from adoption by regulators.

Lawyers also have become aware of the influence of $\mathrm{CDC}$; the potential for being accused of noncompliance with the "national standard" also may oblige hospitals to adopt the Guidelines rather than to make local interpretations.

(3) Certainly much of the reason for the respect with which many view CDC's Guidelines is CDC's consistent record of excellent work in this area over the past two decades. The CDC conducted early systematic data collection that gave us a national estimate of the magnitude of the problem of nosocomial infections. The agency has devoted both money and personnel over the years to the investigation of infection outbreaks in hospitals; many of these studies have given us insight into, and defined techniques to investigate, the epidemiology of nosocomial infections. Most important, however, it was at CDC that many current infection control workersnurses, physicians, microbiologists, administrators, and others-received their initial instructions about coping with infection in hospitals. Thus, a tradition of reliance on the CDC has emerged from their early interest in the area and from the agency's success and efforts in the field.

For all of these reasons it seems that publication of these new CDC Guidelines will attract great interest. Certainly the concurrent publication of a compendium of statements, rather than the prior pattern of release of statements at irregular intervals, should also increase the attention given to these statements.

\section{The Categories}

A major feature of the new Guidelines is that there are not only specific recommendations for and against specific measures, but also a categorization about the relative confidence with which CDC feels that the recommendations should be implemented. In this scheme, a ranking of Category I seems to designate a measure that CDC feels should be adopted throughout the nation, while Categories II and III provide less strong endorsements.

Attempts to quantify the objective basis underlying various control measures is not a new idea; attempts at this have appeared in the literature from the early $1970 \mathrm{~s}^{3}$ through this year. ${ }^{4}$ What is new here is that it is the CDC (the major institutional resource in infection control), rather than an individual, that is indicating its subjective assessment of infection control priorities for the 1980s. This is indeed a commendable project, and a bold and innovative venture for a government agency.

It appears that the attempt has succeeded. There are some aspects that should be particularly useful: (1) provision of a mechanism for addition and revision of Guidelines as new information becomes available; (2) provision in the category format for recommendations advising against certain measures that currently may be employed in some infection control programs; and (3) provision of referenced commentaries before the recommendations are presented, to enable the reader to understand some of the rationale for the recommendations and to seek further reading.

The methods by which these Guidelines and categories were developed are outlined in Dr. Haley's introduction (see page 117 of this issue), and the process seems to have worked remarkably well for the initial attempt at such a large and complicated venture. However, it appears that the role of the working groups is overemphasized in the description of the formulation process. In the group of which I was a member (on Guidelines still being developed), it was quite evident that CDC's Guidelines would be determined finally by CDC itself-as should be the case. Thus, while it is true that, as Haley states, "In all instances thus far, the majority opinions of the working groups have been adopted by CDC," it is also true that the members of the working groups (who, of course, all were selected by $\mathrm{CDC}$ ) worked hard to avoid adopting positions that might necessitate publication of divergent working group and CDC views. In the instances in which there was strong disagreement among members of the working group, intense attempts were made to resolve the issue by rephrasing the wording to achieve wider agreement. Again, this pragmatic approach seems most desirable.

There were some aspects of the process that I felt presented difficulties:

(1) The Categories represent the subjective judgment of CDC about two different factors: the degree to which objective information underlies a recommendation, and a subjective judgment about whether, as stated in the Guidelines, there is "a strong theoretical rationale indicating that [the Guidelines] might be very effective." These dual criteria are difficult to reconcile for many of the Guidelines; readers who have difficulty in deciding why specific Guidelines are in specific categories may well need to remember this dual set of classification criteria.

(2) Because the category definitions are imprecise, the categories themselves had different connotations for different panel members in our working group. Some felt that designation of a Guideline as Category III would remove it from any attempt at implementation. Thus, these individuals considered that all reasonable proposals required a status of Category II or higher. Others viewed Category III primarily as a marker for "important issues that require further evaluation." It appears that there is not yet a clear definition of the significance of Category III. Therefore, Category III is a place in which the word "should" should not appear, because of the legal implications of this word's coming from CDC. 
(3) Some of the working groups included strong advocates for some of the Guidelines that were being considered. This would be analagous to allowing an insurance salesperson to categorize a recommendation to buy more insurance: a certain degree of advocacy is almost inevitable. Although the working group seemed able to allow for such advocacy in making decisions, the process would be more efficient if panels were chosen to provide balance for representation of conflicting positions. Of course, the importance of this is diminished when one remembers that the working groups served only an advisory function.

(4) Designation of category can result from a split vote among the panel. As most disagreements were worked out by the panel members through rephrasing or redrafting the statements, this seems to emphasize the uncertainties of the recommendations made by split vote. Thus, it might be useful in the future to provide some mechanism for dealing with minority opinion when recommendations are made by split decision. These minor matters, however, should not distract from my observation that the advisory process seemed to work smoothly and effectively.

\section{External Review}

Although previous CDC recommendations undoubtedly have utilized the occasional advice of outside experts, the developers of the current Guidelines have gone to great lengths to employ a variety of resources and consultants in attempting "not to arrive at a national consensus of all infection control experts, but to permit CDC recommendations to be tempered by the experience and judgment of a large group of infection control experts who conduct research in hospital epidemiology and actually practice infection control in the practical world of hospitals."

This effort by CDC illustrates that infection control resources have improved. As Schaffner has noted, "The discipline of hospital epidemiology has matured considerably over the past decade." Infection control expertise has been developed in many hospitals in the U.S.A. and elsewhere. Groups devoted to improving our knowledge in this area include the Association for Practitioners in Infection Control (APIC), the new Nosocomial Infections Division of the American Society for Microbiology (ASM), and the Society of Hospital Epidemiologists of America (SHEA). There is a growing interest in the teaching of infection control in universities, and certification and educational requirements are being developed. ${ }^{6,7}$ These developments suggest that the CDC may no longer have to bear the burden of being the only source of infection control knowledge during the coming decade.

To this end, it is encouraging to note that the Hospital Infections Branch of the CDC is now developing proposals for cooperative projects with outside investigators. This is indeed a change, as for most of the past decade CDC research money for extramural cooperative projects in nosocomial infections has been scarce. The current Guidelines should contribute to this new initiative by identifying many infection control recommendations for which further study is required-in fact, this may be the ultimate benefit of Category III.

\section{How Will the Guidelines Be Used?}

Dr. Haley's introduction notes that the major purpose for developing these Guidelines is to disseminate the current opinions of the CDC on various aspects of infection control practice. It emphasizes that "these Guidelines represent the advice of CDC...but are not intended to have the force of law or of regulation." His last paragraph stresses that infection control personnel should "weigh the extent to which each [proposal] would be practical and effective in their particular hospitals." These statements suggest that the Hospital Infection Branch of CDC would like to have their Guidelines considered $a$ source of infection control knowledge, but not the only source. Regulators, lawyers, and we ourselves must remember this.

The Guidelines will be very useful. Because these subjective impressions come from CDC, they should force us to focus our attentions upon the validity of the data that we use to justify our infection control activities, practices, and expenditures. This process of examination will be especially useful for those of us who work in infection control; it also should be helpful to hospital administrators, legislators, regulators, and lawyers. Publication and widespread dissemination of the Guidelines to an even larger group will allow the epidemiologic expertise of the CDC to be enhanced even further by the comments of those whose "day to day experience in practical infection control complements that of hospital epidemiology."

I believe that those of us interested in infection control in hospitals owe Drs. Haley, Hooton, Wong, Simmons, and their colleagues our thanks for this compendium of Guidelines, and for their encouragement to examine closely the foundations of our discipline. When this review is completed, the challenge will still remain to practice effectively what we have become comfortable in preaching. Our need to do both has been emphasized by the SENIC. Project, ${ }^{8}$ the Second International Conference on Nosocomial Infections, ${ }^{9}$ and the International Symposium on Nosocomial Infection Control in Jerusalem. ${ }^{10}$ These CDC Guidelines and categories provide us with a vehicle to begin the process. Let the dialogue continue.

\footnotetext{
John E. Mckowan /r., M.D. Epidemiology Depl (Box I) Grady Memorial Hospital Allanta, (;A 30303 (Address reprint requests to Dr. Mc(jowan)
}

\section{REFERENCES}

1. Buxton AE, Highsmith AK, Garner JS, West C.M, Stamm WF, Dixon RE, et al. Contamination of intravenous infusion: Fffect of changing administration sets. Ann Intern Med 1979; 90:764-8.

2. Centers for Disease Control: Public notice: Guidelines for the prevention and control of nosocomial infections. Morbid Mortal Weekly Report 1981;30-64. 
3. Kass EH. Surveillance as a control system: Statement of panelist. In: Brachman PS, Eickhoff TC (eds). Proceedings of the International Conference on Nosocomial Infections. Chicago, Am Hospital Assn. 1971:292-3.

4. Eickhoff TC. Nosocomial infections-a 1980 view: Progress priorities and prognosis. Am J Med 1981; 70:381-8.

5. Schaffner $W$. Infection control: Old myths and new realities. Infect Control 1980; 1(5):330-4.

6. Shannon RJ. Certification for infection control practitioners: The time is now. Infect Control 1981; 2(1):18-20.
7. APIC Certification Committee: Certification Committee report. Am J Infect Control 1980; 8:64A-65.

8. Haley RW', Quade D, Freeman HE, Bennett JV'. CDC Senic Planning Committee: Study on the Efficary of Nosoromial Infection Control (SENIC Project): Summary of study design. Am J Epidemiol 1980; 111:472-85.

9. Dixon RE (ed). Proceedings of the Second International Conference on Nosocomial Infections. Am J Med 1981; 70:379.473 et seq.

10. Sacks TC, McGowan JE Jr (eds). International Sỵmosium on Nosocomial Infection Control. Rev Infert Dis 1981; (in press).

(Editor's Nole: Readers who would like to submit their own opinions about the Guidelines are encouraged to write to the Editor: Richard P. W'enzel, M.D., Infection Control, 6900 Grove Road, Thorofare, N] 08086. These letters will be published as space permits.) 